\title{
Boas práticas de manipulação em estabelecimentos produtores de alimentos de uma cidade da região noroeste do Rio Grande do Sul
}

\section{Cinara Camara de Oliveira ${ }^{1}$, Carla Cristina Bauermann Brasil ${ }^{2}$, Juliane Pereira da Silva ${ }^{3}$, Larissa Santos Pereira ${ }^{3}$, Daiane Piovesan Verdum¹, Eloa Cristina Camargo Roig ${ }^{1}$, Cariza Teixeira Bohrer $^{4}$, Silvana Moraes Bottaro ${ }^{5}$.}

As condições higiênicas dos estabelecimentos produtores de alimentos dependem da adoção das boas práticas, sendo esta essencial para assegurar a obtenção de alimentos seguros. Assim, o objetivo deste trabalho foi avaliar as boas práticas de manipulação de estabelecimentos produtores de alimentos de Palmeira das Missões-RS. Aplicou-se uma lista de verificação para a categorização dos serviços de alimentação baseada na Portaria $n^{\circ} .817$ de 10 de maio de 2013, contendo 51 itens, em 18 estabelecimentos cadastrados na vigilância sanitária, sendo sete restaurantes comerciais, seis mercados e cinco padarias. A pontuação média geral dos três tipos de estabelecimentos foi de 1503,94 pontos, classificando os locais como "pendente", segundo a metodologia proposta na RDC no. 10/2014. A média geral de adequações verificada foi de $41,7 \%$, sendo que, os índices de adequação obtidos por tipo de estabelecimento foram: 47,9\% em restaurantes, 40,4\% em mercados e 36,7\% em padarias. A categoria com maior percentual de adequação foi referente aos manipuladores de alimentos (72,8\%). As maiores não conformidades foram observadas na categoria de responsabilidade, documentação e registro $(20,5 \%)$ e estrutura física $(26,1 \%)$. Ressalta-se a necessidade de adequações de acordo com as legislações vigentes e maior fiscalização da vigilância sanitária nestes estabelecimentos.

Palavras-chave:Legislação sobre alimentos. Manipulação de Alimentos. Qualidade dos alimentos.

\section{Good handling practices in food establishments in a northwest city of Rio Grande do Sul}

The hygienic conditions of food-producing establishments are related to the adoption of best practices, which is essential to ensure a safe product. Thus, the aim of this study was to evaluate the good handling practices in food producer establishments in the city of Palmeira das Missões - RS. A checklist containing 51 items for classifying food services was used, based on the the Ordinance number $817 / 2013$. Eighteen establishments registered in the sanitary surveillance system were investigated, of which seven were restaurants, six supermarketsand five bakeries. The average score of the three types of establishments was 1503.94 points, classifying them as "unresolved establishments", according to the methodology proposed in RDC number 10/2014. The mean percentage of adjustments was $41.7 \%$, being $47.9 \%$ in commercial restaurants; $40.4 \%$ in supermarkets; and $36.7 \%$ in bakeries. The food

${ }^{1}$ Nutricionista formada pela Universidade Federal de Santa Maria.

${ }^{2}$ Profa. Dra. em Ciência e Tecnologia de Alimentos, Docente do curso de Nutrição da Universidade Federal de Santa Maria - campus de Palmeira das Missões. Endereço para Correspondência: Av. Independência, 3751 Vista Alegre, 98300-000 Palmeira das Missões - RS, Brasil. Telefone: (55) 99973-3165.E-mail. carlacristina@ brturbo.com.br.

${ }^{3}$ Acadêmica do curso de Nutrição da Universidade Federal de Santa Maria.

${ }^{3}$ Acadêmica do curso de Nutrição da Universidade Federal de Santa Maria.

${ }_{5}^{5}$ Profa. Dra. em Saúde da Criança e do Adolescente, Docente do curso de Nutrição da Universidade Federal de Santa Maria (UFSM) - campus de Palmeira das Missões 
handling category exhibited the highest adequacy percentage $(72.8 \%)$. The higher number of nonconformities were observed in the categories responsibility, documentation and registration $(20.5 \%)$, and physical structure $(26.1 \%)$. Thus, adaptations according to the current legislation and better sanitary surveillance supervision in these establishments are needed.

Keywords: Legislation. Food. Food handling. Foodquality.

\section{INTRODUÇÃO}

A alimentação humana deve apresentar qualidade higiênico-sanitária e adequado teor nutricional dos alimentos para suprir as necessidades fisiológicas dos indivíduos ${ }^{[1,2]}$. Assim, os aspectos como higiene, qualidade, segurança alimentar e confiabilidade dos produtos são fatores determinantes na aquisição de gêneros alimentícios em estabelecimentos produtores de alimentos. De fato, a qualidade duvidosa de um produto, além de diminuir a credibilidade do estabelecimento que o fornece, pode trazer prejuízos à saúde dos consumidores $^{[3,4]}$.

O conceito de qualidade inclui não só características de sabor, aroma e aparência, mas também o cuidado em adquirir alimentos que não causem danos à saúde, como doenças transmitidas por alimentos (DTAs). Alimento seguro é aquele que não oferece perigo à saúde e à integridade do consumidor. Esses perigos podem ser biológicos (bactérias, vírus, fungos, entre outros), químicos (agrotóxicos, produtos químicos, inseticidas, entre outros) e físicos (materiais como pregos, vidros, plásticos, entre outros $)^{[5,6,7]}$.

As DTAs são responsáveis pela ocorrência de surtos de pequenas, médias e grandes proporções ao redor do mundo. Os surtos são considerados os episódios em que duas ou mais pessoas apresentam os mesmos sinais/sintomas após ingerir alimentos e/ou água da mesma origem ${ }^{[8,9]}$. No Brasil, entre os anos de 2007 a 2016 ocorreram cerca de 6.848 surtos de DTAs acometendo 121.283 pessoas e levando a 111 óbitos. Dentre esses casos,
16,10\% tiveram como local de ocorrência restaurantes, padarias ou similares ${ }^{[10]}$.

A identificação do alimento causador da DTA muitas vezes é dificultada, pois a maioria está relacionada com a ingestão de alimentos com características sensoriais (aparência, sabor, odor) inalteradas. Além disso, os manipuladores responsáveis pelo preparo dos alimentos, podem ter relação direta com a contaminação dos alimentos consumidos ${ }^{[11,12,13]}$.

A qualidade dos alimentos e as condições higiênico-sanitárias dos estabelecimentos produtores de alimentos estão relacionadas com a forma de execução e controle dos processos de produção. Estes processos podem ser verificados através de critérios, tais como: abastecimento e qualidade da água; hábitos e atitudes dos manipuladores; qualidade das matérias-primas ingredientes e embalagens; armazenamento, transporte e exposição do alimento preparado em condições ideais. Além disso, a realização de controles, registros dos processos e capacitação dos manipuladores, são atividades imprescindíveis e podem auxiliar na prevenção da ocorrência de surtos de doenças transmitida por alimentos $[7,14,15,16]$

Desse modo, foram criadas pela Agência Nacional de Vigilância Sanitária (ANVISA), legislações que servem como ferramentas de garantia de qualidade para os estabelecimentos produtores e comercializadores de alimentos, como a RDC $\mathrm{n}^{\circ} .216$ de 15 de setembro de $2004^{[17]}$, que estabelece os procedimentos de Boas Práticas para serviços de alimentação a fim de garantir 
as condições higiênico-sanitárias do alimento preparado. Com o mesmo propósito, o Ministério da Saúde (MS), criou a Portaria $n^{\circ}$. $817 / 2013^{[18]}$, que aprova as diretrizes nacionais para a elaboração e execução do projeto-piloto de categorização dos serviços de alimentação para a Copa do Mundo no Brasil. Destaca-se que apesar desta Portaria ter sido elaborada para a aplicação exclusiva neste evento, a ferramenta é bastante útil para sistematizar a avaliação das condições higiênico-sanitárias dos serviços de alimentação, pela sua metodologia. Ainda, salienta-se que neste projeto piloto $^{[18]}$, dos 180 critérios previstos na RDC $n^{\circ}$. $216 / 2004^{[17]}$, foram considerados os 51 de maior impacto à saúde.

Tendo em vista que as boas práticas são essenciais para garantir a qualidade sanitária dos alimentos, a aplicação da lista de verificação permite identificar pontos de não conformidade e mediante a isto, traçar ações corretivas, paliativas e de longo prazo. Dessa forma, este estudo se justifica pela necessidade de avaliar as boas práticas de manipulação durante a produção de alimentos, visando atender às exigências legais e, dessa forma, garantir a qualidade e segurança dos alimentos.

\section{METODOLOGIA}

\section{Características do estudo}

Trata-se de um estudo observacional do tipo transversal quali-quantitativo de avaliação de boas práticas de manipulação empregadas em estabelecimentos produtores de alimentos de Palmeira das Missões-RS.

A pesquisa foi conduzida em estabelecimentos produtores de alimentos (restaurantes comerciais, mercados e padarias) registrados e fiscalizados pela Vigilância Sanitária (VISA) no ano de 2015.

Foram avaliados os locais que assinaram o termo de autorização para o desenvolvimento da pesquisa, ou seja, 53,8\% $(n=7)$ dos restaurantes comerciais, 8,1\% $(\mathrm{n}=6)$ dos mercados e $45,4 \% \quad(n=5)$ das padarias do município avaliado, totalizando 18 estabelecimentos produtores de alimentos, considerada uma amostra representativa.

Os estabelecimentos vistoriados foram identificados por números para manter o sigilo dos dados, sendo restaurantes comerciais (1-7), mercados (1-6) e padarias (1-5).

\section{Aplicação da lista de verificação}

A aplicação da lista de verificação de boas práticas ocorreu após a finalização dos contatos com os estabelecimentos produtores de alimentos cadastrados na vigilância sanitária do município de Palmeira das Missões - RS que solicitaram a renovação do alvará sanitário em 2015.

A coleta de dados foi realizada por profissionais capacitados juntamente com os fiscais da Vigilância Sanitária municipal.

O estudo utilizou como ferramenta uma lista de verificação em boas práticas baseada na Portaria $\mathrm{n}^{\circ} .817 / 2013^{[18]}$, contendo 51 itens, subdivididos em nove categorias (QUADRO 1).

Quadro 1 - Categorias avaliadas na lista de verificação da Portaria nº 817/2013 aplicada aos estabelecimentos produtores de alimentos.

\begin{tabular}{|l|c|}
\hline \multicolumn{1}{|c|}{ Categorias avaliadas } & $\begin{array}{c}\text { Número de } \\
\text { itens }\end{array}$ \\
\hline Abastecimento de água (Categoria A) & 7 \\
\hline Estrutura (Categoria B) & 2 \\
\hline Higienização de instalações, equipamentos, móveis e utensílios (Categoria C) & 6 \\
\hline
\end{tabular}




\begin{tabular}{|l|c|}
\hline Controle integrado de vetores e pragas urbanas (Categoria D) & 3 \\
\hline Manipuladores (Categoria E) & 3 \\
\hline Matéria-prima, ingredientes e embalagens (Categoria F) & 7 \\
\hline Preparação do alimento (Categoria G) & 12 \\
\hline Armazenamento, transporte e exposição do alimento preparado (Categoria H) & 9 \\
\hline Responsabilidade, documentação e registro (Categoria I) & 2 \\
\hline
\end{tabular}

Fonte: Portaria nº. 817/2013[18].

A lista de verificação da Portaria $n^{\circ}$. $817 / 2013^{[18]}$ conta com um sistema de pontuação segundo critérios de risco, são eles: Indice de Impacto (IIp) e Carga Fatorial (CF), que foram utilizados para a obtenção da pontuação final do estabelecimento avaliado. $\mathrm{O}$ valor, denominado Índice de Impacto, representa a relevância do item na prevenção de uma DTA. Quanto maior a relevância, maior é o IIp. Para a pontuação do item, o IIp deve ser multiplicado pela Carga Fatorial (CF). O IIp e a CF de cada item estão disponíveis na Portaria $\mathrm{n}^{\circ}$. 817/2013 ${ }^{[18]}$. A nota final do estabelecimentoserá obtida pela soma da pontuação de cada item. Os itens de avaliação ainda se subdividem em: Eliminatórios (3 itens), classificatórios (2 itens) e pontuados (46 itens que dispõem de IIp e CF). A avaliação dos estabelecimentos produtores de alimentos destinou-se ao cumprimento da Portaria $\mathrm{n}^{\circ}$. $817 / 2013^{[18]}$, onde através da implantação da mesma pode-se garantir a segurança do alimento oferecido e/ou comercializado.

As opções de respostas para o preenchimento da lista de verificação foram: "Adequado" (AD) - quando o estabelecimento atendeu ao item observado, "Inadequado" (IN) - quando o estabelecimento apresentou não conformidade para o item observado, "Não Aplicável" (NA) - quando o item foi considerado não pertinente ao local pesquisado. Os itens, cuja resposta foi a opção "Não Aplicável", não foram avaliados.

A classificação dos estabelecimentos foi realizada de acordo com a RDC $\mathrm{n}^{\circ} .10$ de 12 de março de $2014^{[19]}$, que divide os estabelecimentos em quatro categorias (QUADRO 2).

Quadro 2 - Categorias dos serviços de alimentação e condições necessárias:

\begin{tabular}{|c|l|}
\hline Categoria & \multicolumn{1}{c|}{ Condição necessária } \\
\hline $\mathrm{A}$ & $\begin{array}{l}\text { Pontuação } \geq \text { que } 0 \text { e }<\text { que 13,3, cumprimento dos itens eliminatórios e de, pelo } \\
\text { menos, um dos itens classificatórios. }\end{array}$ \\
\hline $\mathrm{B}$ & Pontuação $\geq$ que 13,3 e $<$ que 502,7 e cumprimento dos itens eliminatórios. \\
\hline C & Pontuação $\geq$ que 502,7 e $<$ que 1152,3 e cumprimento dos itens eliminatórios \\
\hline Pendente & Pontuação $\geq$ que 1152,3 e ou descumprimento dos itens eliminatórios. \\
\hline
\end{tabular}

Fonte: Brasil (2014) ${ }^{[19]}$.

Para obtenção da pontuação final de cada estabelecimento foi utilizado o Sistema de Avaliação de Risco Sanitário em Serviços de Alimentação, versão $1.0^{[20]}$. Este sistema gera relatórios específicos para avaliação e monitoramento das condições higiênico- sanitárias em serviços de alimentação sendo a pontuação apresentada em percentuais de adequação.

Quando aplicável, as temperaturas dos equipamentos dos estabelecimentos produtores de alimentos (freez̧ers, geladeiras, câmaras frias, 
fritadeiras e balcões de distribuição de alimentos, entre outros) foram verificadas por um termômetro digital de profundidade (tipo espeto) da marca ThermometermodeloPrecision com faixa de leitura entre $-50{ }^{\circ} \mathrm{C} \mathrm{e}+300{ }^{\circ} \mathrm{C}$.

\section{Estatística}

Os dados coletados foram digitados e tabulados com o auxílio do programa Microsoft Office Excel®, versão 2007 e as figuras formuladas através do programa GraphPad Prism versão 5.0. Os dados foram submetidos à análise estatística descritiva simples (média e percentual de conformidade), com auxílio do programa Statistica versão 7.0.

\section{RESULTADOS E DISCUSSÃO}

A pontuação média geral de não conformidades dos estabelecimentos produtores de alimentos foi de 1503,94pontos, estando somente $41,7 \%$ dos itens em conformidade e classificando os locais avaliados como "pendentes" segundo os critérios propostos na RDC no $10 / 2014^{[19]}$.

A média de adequação geral dos restaurantes comerciais, mercados e padarias foi de $47,9 \%, 40,4 \%$ e $36,7 \%$, respectivamente. Estes baixos percentuais evidenciam a vulnerabilidade dos estabelecimentos avaliados, o que pode ser considerado um risco à ocorrência de doenças transmitidas por alimentos.
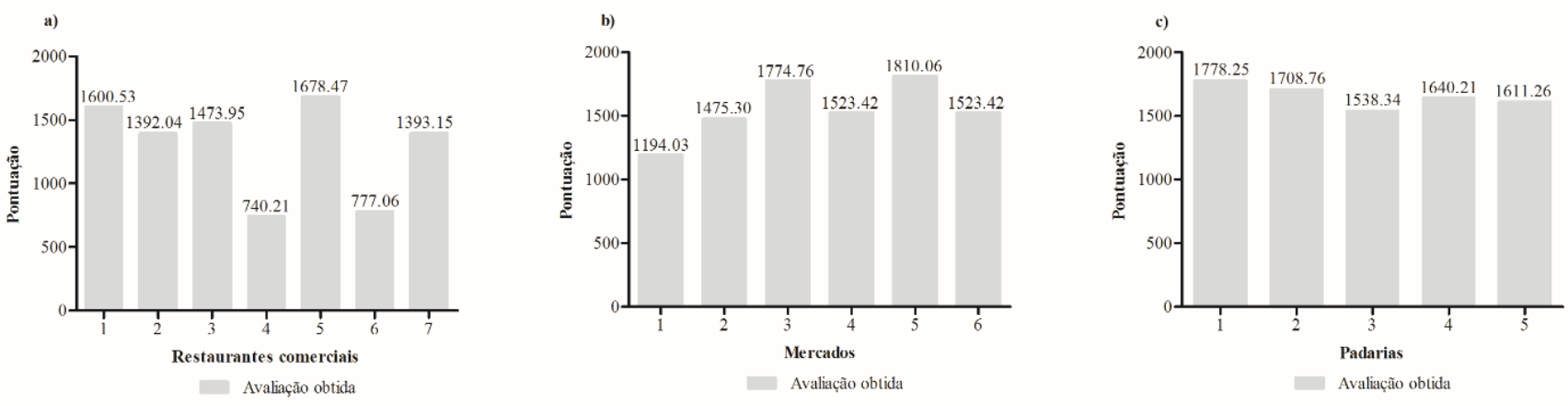

Figura 1 - Pontuação geral de não conformidades por tipo de estabelecimento avaliado da cidade de Palmeira das Missões - RS.

Fonte: Autor, 2017.

Dos estabelecimentos avaliados $88,9 \%$ $(\mathrm{n}=16)$, enquadraram-se na categoria "pendentes", enquanto que o restante dos locais foi classificado como Grupo C (pontuação entre 502,7 e 1152,3 e cumprimento dos itens eliminatórios), sendo esses restaurantes comerciais (Figura 1a). São três os itens eliminatórios, e dizem respeito aos aspectos que apresentam maior impacto para saúde, como a utilização de água potável nas atividades de manipulação, abastecimento com água corrente e existência de conexões com rede de esgoto ou fossa séptica. Em casos de não cumprimento destes itens, o local deve passar por readequação. A pontuação média geral obtida nos mercados foi 1550,2 e padarias 1655,4 sendo classificado como "pendente" (Figura 1b e 1c). Este dado é preocupante visto que 
os estabelecimentos que se enquadram neste grupo não são categorizados, pois não cumprem os itens eliminatórios da lista de verificação utilizada, apresentando qualidade sanitária inaceitável para funcionamento

As categorias que apresentaram melhor nível de adequação na lista de verificação foram relacionadas aos manipuladores (Categoria E) e controle integrado de vetores e pragas urbanas (Categoria D), as demais categorias avaliadas ficaram com percentuais abaixo de 45\% (Figura 2). Estes dados evidenciam que os estabelecimentos avaliados não apresentam elementos essenciais para reduzir os riscos de contaminação dos alimentos, tais como: ausência de capacitação dos manipuladores de alimentos em boas práticas e não

conformidades nas ferramentas de controle e gerenciamento de um estabelecimento produtor de alimentos.

$\mathrm{Na}$ categoria referente ao abastecimento de água (Figura 2) os estabelecimentos avaliados apresentaram um percentual de adequação semelhante ao encontrado por Reis, Flávio e Guimarães ${ }^{[21]}$ em estudo realizado em uma unidade de alimentação e nutrição hospitalar de Montes Claros-MG. A presente pesquisa mostra que as maiores não conformidades estavam relacionadas à inexistência de conexões das instalações com rede de esgoto ou fossa séptica e ausência de abastecimento com água corrente. Os mercados foram os estabelecimentos que apresentaram maior percentual de adequação nesta categoria $(45,67 \%)$, os restaurantes por sua vez obtiveram somente $29 \%$ de adequação.

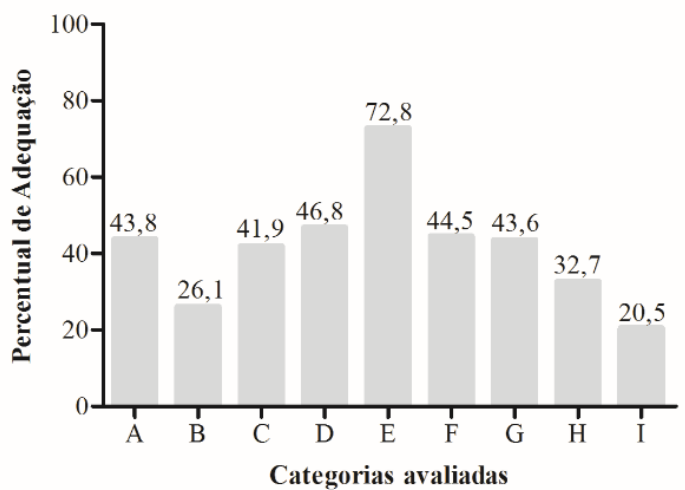

Figura 2 - Percentual de adequação geral por categoria dos estabelecimentos produtores de alimentos avaliados da cidade de Palmeira das Missões - RS.

Nota: Categoria A - Abastecimento de água; Categoria B - Estrutura; Categoria C - Higienização de instalações. Equipamentos, móveis e utensílios; Categoria D - Controle integrado de vetores e pragas urbanas; Categoria E - Manipuladores; Categoria F - Matéria prima, ingredientes e embalagens; Categoria G - Preparação do alimento; Categoria $\mathrm{H}$ - Armazenamento, transporte e exposição do alimento preparado; Categoria I Responsabilidade, documentação e registro.

Fonte: Autor, 2017.

Salienta-se que a água é utilizada em todas as etapas operacionais dentro de um estabelecimento produtor de alimentos, podendo atuar como ingrediente na preparação e/ou auxiliar no processo de higienização de superfícies e alimentos. Por ser um item eliminatório ${ }^{[19]}$, apresenta um grau de risco sanitário relevante, e o baixo percentual de adequação obtido nesta categoria, em todos os tipos de estabelecimentos avaliados, merece atenção especial. Dessa forma, cabe destacar aos responsáveis pelo estabelecimento a importância de realizar o controle de qualidade da mesma, evitando assim, possíveis riscos de contaminação e danos a saúde do consumidor. Segundo a RDC $n^{\circ}$. 216/2004 ${ }^{[17]}$ deve ser utilizada somente água potável para manipulação e distribuição de alimentos, sendo que o reservatório de água deve ser revestido de materiais que não comprometam a qualidade da água, além disso, devem estar livres de rachaduras, vazamentos, infiltrações e descascamentos.

Em relação à categoria estrutura física (Figura 2), o índice de conformidades encontrado nesse estudo evidencia condições higiênicas precárias nos estabelecimentos. Ao avaliar os dados obtidos constatou-se que os mercados apresentaram $37,5 \%$ de adequação nesta categoria, sendo os locais com a maior pontuação. Em contrapartida, os restaurantes 
comerciais foram os que apresentaram menor percentual $(12,8 \%)$, pois não apresentavam produtos de higiene pessoal adequados e não possuíam separação entre as diferentes etapas operacionais de produção, podendo ocasionar o risco de contaminação cruzada entre os alimentos. As não conformidades encontradas neste estudo, assemelham-se às observadas por Sobral et al. ${ }^{[22]}$, em um mercado público da cidade de Russas-CE. Os autores observaram que as instalações sanitárias se encontravam em péssimo estado de conservação, o acesso não era restrito aos manipuladores de alimentos, e, além disso, que os lavatórios não possuíam os itens necessários para a higienização de mãos e lixeiras adequadas para o descarte de resíduos. Já em pesquisa realizada por Lopes, Silveira e Floriano $^{[23]}$ no setor hoteleiro da cidade de Uruguaiana-RS, observaram que $80 \%(n=8)$ dos locais não apresentavam separação entre as diferentes atividades, seja por meios físicos ou por outros meios de forma a evitar a contaminação cruzada. Desse modo, para garantir condições higiênico-sanitárias adequadas é imprescindível que a estrutura física também esteja em conformidade com a legislação sanitária vigente.

Ao avaliar a categoria higienização de instalações, equipamentos, móveis e utensílios (Figura 2) os estabelecimentos apresentaram um percentual de adequação diferente do encontrado por Raimundo et al. ${ }^{[24]} \mathrm{em}$ seis serviços de alimentação do mercado municipal de Curitiba-PR. Segundo os autores, itens relacionados a higienização e condutas interferem diretamente na qualidade $e$ segurança dos alimentos. Pode-se constatar que os itens que apresentaram maior conformidade no presente estudo se relacionavam a conservação e limpeza dos equipamentos, móveis e utensílios (44,4\%). As não conformidades observadas nesta categoria referem-se principalmente à ausência de higienização frequente nas áreas de preparação e utilização dos mesmos utensílios para higienização das instalações e equipamentos. Nesta categoria, o melhor percentual de adequação foi obtido pelos mercados (45,2\%), os restaurantes e padarias por sua vez, apresentaram apenas $43,7 \%$ e $35,6 \%$ de conformidades, respectivamente (Figura 2). Além de manter as instalações, equipamentos, móveis e os utensílios em condições higiênicosanitárias apropriadas, deve-se efetuar o registro dessas operações em planilhas de controle quando as mesmas não forem realizadas rotineiramente ${ }^{[17]}$. É fundamental que a execução dessas operações de higienização seja realizada por profissionais capacitados, minimizando assim, o risco de contaminação dos alimentos ${ }^{[15]}$.

Quanto ao controle de vetores e pragas urbanas (Figura 2) os mercados apresentaram $32 \%$ dos itens observados em conformidade, sendo este o menor percentual de adequação obtido. Em contrapartida, os restaurantes e padarias apresentaram $72,7 \%$ e $49,2 \%$ de conformidades, respectivamente. Em estudo realizado por Silveira et al. ${ }^{[25]}$ em 24 serviços de alimentação, incluindo dez restaurantes comerciais, sete lanchonetes, cinco padarias e dois hotéis, a maior média de adequação obtida nesta categoria $(63,2 \%)$, resultado este correlacionado à facilidade de atendimento dos requisitos. No presente estudo, o controle de pragas foi a segunda categoria que apresentou maior percentual de adequação, sendo que o item com maior conformidade se referia ao ambiente estar livre da presença de animais $(55,6 \%)$, incluindo vetores e pragas urbanas, podendo assim ser considerado um fator positivo, visto que os mesmos podem representar importante ameaça a inocuidade dos alimentos produzidos. É importante salientar que para que um estabelecimento seja isento de vetores e pragas urbanas é necessário um conjunto de ações eficientes e contínuas de controle visando minimizar a atração, abrigo, acesso e/ou proliferação dos mesmos. Vale ressaltar que a execução do controle químico deve ser feita por empresa especializada, além disso, os produtos devem ser regularizados pelo Ministério da Saúde ${ }^{[17,26]}$, contrariando os resultados verificados na presente pesquisa. 
$\mathrm{Na}$ categoria referente aos manipuladores de alimentos (Figura 2) os estabelecimentos apresentaram um resultado semelhante ao evidenciado por Silva et al. ${ }^{[27]} \mathrm{em}$ duas unidades de alimentação e nutrição localizadas no município de Vitória-ES, onde foram observados hábitos inadequados como falar e tossir durante a manipulação dos alimentos. Além disso, no presente estudo pode-se constatar ausência de higienização das mãos e presença de adornos nos manipuladores durante a produção e distribuição dos alimentos. Os restaurantes comerciais foram os estabelecimentos que apresentaram maior percentual de conformidades nesta categoria, totalizando $89 \%$ de adequação. Em contrapartida, as padarias obtiveram $48,2 \%$ de adequação. Ainda assim, esta foi a categoria com maior percentual de conformidades no estudo (Figura 2), o que pode ser considerado um aspecto positivo, visto que o manipulador é considerado um dos principais responsáveis pela contaminação dos alimentos ${ }^{[10]}$. $\mathrm{Na}$ grande maioria das vezes esta contaminação ocorre pela ausência de higienização das mãos, ocasionando transmissão de microrganismos para os alimentos como Staphylococcus aureus, mesófilos e coliformes totais ${ }^{[28]}$. Nesse contexto, cabe salientar a importância da atuação de profissionais capacitados e/ou de nutricionistas nos estabelecimentos, pois os mesmos trabalham com o intuito de garantir o funcionamento do local de acordo com as legislações sanitárias vigentes. A realização de capacitações periódicas, orientação em relação correta higienização das mãos, ausência de adornos durante a manipulação e a conscientização desses profissionais no seu papel na segurança dos alimentos são atividades que contribuem para o aumento da qualidade do alimento comercializado.

Em relação à matéria-prima, ingredientes e embalagens (Figura 2) o nível de adequação encontrado foi semelhante ao apresentado em estudos realizados por Silva et al. ${ }^{[27]}$ e Santos et al. ${ }^{[29]}$. O baixo percentual de adequação verificado em ambos os estudos é decorrente da falta de inspeção no recebimento das mercadorias, organização e identificação das matérias-primas e ausência de equipamentos de monitoramento de temperatura. O presente estudo também ressalta não conformidades nos mesmos itens, sendo a maior incidência relacionada à verificação da temperatura no recebimento e armazenamento das matériasprimas e ingredientes perecíveis. Destaca-se que $83,3 \%(n=15)$ dos estabelecimentos avaliados não faziam este controle, sendo 100\% $(n=7)$ dos restaurantes comerciais, 83,3\% $(n=5)$ dos mercados e $60 \% \quad(n=3)$ das padarias. A exposição dos alimentos a temperaturas inadequadas, causada pela ausência de controle dasmesmas, pode promover a proliferação e crescimento de bactérias patogênicas, aspecto este que constitui alto risco para o surgimento de surtos de DTAs ${ }^{[10,17]}$.

O maior percentual de adequação da categoria relacionada a matéria-prima, ingredientes e embalagens foi obtido nos restaurantes comerciais (53,5\%), entretanto, $57,1 \% \quad(n=4) \quad$ dos estabelecimentos não apresentaram adequado fracionamento e identificação das matérias-primas nos estoques. O menor percentual de adequação foi obtido pelas padarias (33\%), este dado se explica pela ausência de condições higiênicas adequadas nas matérias-primas, ingredientes e embalagens de todas as padarias visitadas, fato este que poderia ser minimizado pela presença de responsáveis capacitados e/ou nutricionistas nos locais. Para que seja garantida a inocuidade do alimento, é indispensável a inspeção e utilização das matérias-primas de acordo com o prazo de validade ou ordem de entrada, a manutenção de temperaturas adequadas nas diferentes etapas de produção e distribuição, além do adequado fracionamento e identificação das mesmas. Caso não seja efetuada estas ações o alimento é exposto a riscos de contaminação aumentando assim as chances de DTAs ${ }^{[10,17]}$.

$\mathrm{Na}$ categoria referente à preparação do alimento (Figura 2) os restaurantes 
apresentaram 54,1\% de conformidades, sendo este o maior percentual da categoria, pois os mercados e padarias obtiveram $38 \%$ e $35,6 \%$ de adequação, respectivamente. As não conformidades observadas são muito semelhantes às encontradas por Silva et al. ${ }^{[30]}$ em uma cozinha hospitalar de Porto Alegre-RS, onde produtos perecíveis ficavam expostos à temperatura ambiente por mais de 30 minutos e alimentos no processo de descongelamento encontravam-se sem refrigeração, sob bancadas da área de manipulação. Além disso, as não conformidades citadas relacionavam-se a ações que aumentam o risco de contaminação cruzada, como ausência de higienização das mãos na troca de atividades e manipulação de alimentos crus na mesma bancada que em que eram manipulados os alimentos cozidos.

O manipulador exerce um papel importante na determinação da inocuidade dos alimentos servidos, pois, se não realizar uma higienização adequada das mãos, das bancadas e dos utensílios que serão utilizados, há um grande risco do alimento se contaminar assim que entrar em contato com estas superfícies ${ }^{[4,15]}$. Nesse sentido, torna-se indispensável a adoção de ações voltadas à higiene pessoal e preparo dos alimentos de forma segura, como capacitações baseadas nas boas práticas de manipulação, que podem melhorara qualidade dos serviços prestados ${ }^{[15]}$.

Quanto ao armazenamento, transporte e exposição do alimento preparado (Figura 2), obteve-se um percentual distinto do encontrado por Mayra et al. ${ }^{[31]}$ que descreveu $100 \%$ de adequação em seu estudo envolvendo duas unidades hoteleiras do município de CaruaruPE. As principais não conformidades observadas no presente estudo se relacionavam a temperatura inadequada de conservação dos alimentos (abaixo de $\left.60^{\circ} \mathrm{C}\right)^{[17]}$ e a ausência de monitoramento da mesma, sendo que os estabelecimentos não possuíam termômetros. Os restaurantes apresentaram $35,6 \%$ de adequação, sendo esta a melhor porcentagem da categoria, os mercados por sua vez obtiveram a menor porcentagem, sendo correspondente a $29 \%$ de adequação. A falta de mão de obra capacitada, equipamentos de conservação a frio ou a quente, e espaço físico são os principais motivos pelas não conformidades no controle do binômio tempotemperatura em serviços de alimentação ${ }^{[32,33]}$. A temperatura adequada, tanto no armazenamento como na distribuição contribui para a garantia da qualidade das refeições. Por isso, deve ser monitorada constantemente, por profissionais capacitados, minimizando os riscos de contaminação e crescimento microbiológico e, evitando assim, possíveis riscos de doenças transmitidas por alimentos ${ }^{[17]}$.

A categoria responsabilidade, documentação e registro (Figura 2) apresentou o menor índice de conformidades do estudo, o que se explica pela ausência de responsáveis comprovadamente capacitados, Manual de Boas Práticas (MBP) e Procedimentos Operacionais Padronizados (POPs) implantados na maioria dos estabelecimentos avaliados. Apenas 50\% $(n=3)$ dos mercados e $20 \%(n=1)$ das padarias possuíam responsável capacitado pelas atividades de manipulação dos alimentos, ao mesmo tempo estes foram os estabelecimentos que apresentaram menor índice de adequação nesta categoria, ambos com 20\%. Já os restaurantes foram os locais que apresentaram maior percentual de adequação nesta categoria $(21,4 \%)$, e por este ser um percentual muito baixo, torna-se um dado preocupante que merece atenção.

Segundo Libanio, Gondim e Sousa ${ }^{[34]}, \mathrm{O}$ MBP é um documento que descreve os métodos adotados pela empresa para cumprir aos requisitos estabelecidos na legislação vigente, visando à produção de alimentos inócuos. Os autores ainda destacam a importância da elaboração e implementação do MBP e dos POPs, pois, seguindo essas orientações, o estabelecimento estará se adequando às exigências legais e cooperando para melhoria na qualidade das refeições produzidas. Destaca-se ainda que a presença 
dessa documentação não garante a inocuidade do alimento fornecido, sendo que esta só vai ser assegurada quando as recomendações escritas nestes documentos forem colocadas em prática.

\section{CONCLUSÃO}

Observou-se com a aplicação da lista de verificação, que os 18 estabelecimentos produtores de alimentos avaliados apresentaram condições higiênicas insatisfatórias, classificando a maioria deles na categoria pendentes.

Identifica-se a necessidade de adequações dos processos relacionados à produção e distribuição de alimentos. As maiores não conformidades foram observadas nas categorias referentes à estrutura, responsabilidade, documentação e registro, armazenamento, transporte e exposição do alimento preparado e higienização de instalações equipamentos, móveis e utensílios, sendo estes os itens que merecem atenção prioritária, em virtude dos riscos de ocorrências de DTAs e demais perigos que podem representar para a saúde do consumidor.

Estes achados evidenciam a importância da atuação de responsáveis capacitados no gerenciamento dos estabelecimentos produtores de alimentos, na execução de capacitações dos colaboradores, bem como na implementação de ações e processos visando à minimização dos riscos de contaminação alimentar, proporcionando aos consumidores qualidade nos serviços prestados.

Recomenda-se maior atenção e fiscalização da vigilância sanitária, com o objetivo de garantir o funcionamento destes estabelecimentos de acordo com as legislações sanitárias vigentes.

\section{REFERÊNCIAS}

[1] Souza MS, Medeiros LB, Saccol ALF. Implantação das boas práticas em uma unidade de alimentação e nutrição (UAN) na cidade de Santa Maria - RS. Alim. Nutr. Braz. J. Food Nutr., Araraquara, 2013 abr-jun; 24(2): 203-207.

[2] Busato MA, Pedrolo C, Gallina LS, da Rosa L. Ambiente e alimentação saudável: percepções e práticas de estudantes universitários. Semina: Ciências Biológicas e da Saúde, Londrina. 2015 juldez; 36(2): 75-84.

[3] Vieira ACP, Buainain AM, Spers EE. A segurança do alimento e a necessidade da informação aos consumidores. Cadernos de Direito, Piracicaba. 2010 jul-dez; 10(19): 21-37.

[4] Veloso TNN, Primo NC, Faria AA. Avaliação microbiológica e sanitária de cachorros-quentes comercializados por ambulantes em Barra do Garças-MT. Rev. eletrônica da UNIVAR. 2014; 2(12): 77-82.

[5] Brasil. Ministério da Agricultura, Pecuária e Abastecimento. Produção integrada no Brasil: agropecuária sustentável alimentos seguros. Secretária de Desenvolvimento Agropecuário e Cooperativismo. - Brasília: Mapa/ACS, 2009. [Acesso em: 25 jan. 2017].

[6] Rios TC. Boas práticas em supermercados e na central de armazenamento e distribuição. [Monografia]. Porto Alegre RS: Universidade Federal do Rio Grande do Sul; 2012.

[7] Conceição MS, Nascimento KO. Prevenção da transmissão de patógenos por manipuladores de alimentos. Rev. Verde. 2014 dez; 9(5): 91-97.

[8] Dias RS, Bernardes AFL, Zuccoli PC. A importância do processo de investigação na elucidação de surtos de Doenças Transmitidas por Alimentos (DTA). In: $26^{\circ}$ Congresso Brasileiro de Microbiologia, (SBM), dez. 2011; Belo Horizonte, MG, periódico cientifico do núcleo de biociências centro universitário metodista Isabela Hendrix; dez. 2011. p. 17-23.

[9] Guarda VLM, Bornachi AF, Rocha BT, Rodrigues TS. A importância da qualificação de manipuladores de alimentos: estudo de caso na produção de salgados na cidade de Mariana/MG. 
Caminho Aberto - Revista de Extensão do IFSC. nov.2015; 1(3): 14-22.

[10] Brasil. Ministério da Saúde. Secretaria de Vigilância em Saúde. Vigilância epidemiológica das doenças transmitidas por alimentos 2016 [acesso em 11 mai 2017]. Disponível em: http://portalarquivos.saude.gov.br/images/pdf/20 16/dezembro/09/Apresentacao-Surtos-DTA2016.pdf

[11] Oliveira ABA, de Paula CMD, Capalonga R, Cardoso MRI, Tondo EC. Doenças transmitidas por alimentos, principais agentes etiológicos e aspectos gerais: uma revisão. Rev. Hospital de Clinicas Porto Alegre. 2010; 30(3): 279-285.

[12] Almeida JC, de Paula CM, Svoboda WK, Lopes MO, Pilonetto MP, Abrahão WM et al. Perfil epidemiológico de casos de surtos de doenças transmitidas por alimentos ocorridos no Paraná, Brasil. Semina: Ciências Biológicas e da Saúde, Londrina. 2013 jan-jul; 34(1): 97-106.

[13] Braga AC, Pereira TL, Junior PPA. Avaliação de restaurante universitário por meio de indicadores de qualidade. Desenvolvimento em Questão. 2015 abr-jun; (30): 306-326.

[14] Messias GM, Reis MER, Soares LP, Fernandes NM, Duarte ES. Avaliação das condições higiênicosanitárias de restaurantes do tipo self service e do conhecimento dos manipuladores de alimentos quanto à segurança do alimento na cidade do Rio de Janeiro, RJ. Rev. Eletrônica Novo Enfoque, 2013; 17(17): 73-88.

[15] Ávila MO, Santos PHS, Gois FN, Furtado MC, Reis IAO. A importância do controle das condições microbiológicas e higiênico sanitárias na prevenção de doenças transmitidas por alimentos - Uma revisão de literatura. Rev. Expressão Científica. 2016; 1(1): 1-12.

[16] Mello JF, Schneider S, Lima MS, Frazzon J, Costa M. Avaliação das condições de higiene e da adequação as boas práticas em unidades de alimentação e nutrição no município de Porto Alegre - RS. Alim. Nutr. Braz. J. Food Nutr., Araraquara, 2013 abr-jun; 24(2): 175-182.

[17] Brasil. Ministério da Saúde. Agência Nacional de Vigilância Sanitária. RDC no. 216, de 15 de setembro de 2004. Dispõe sobre o Regulamento Técnico de Boas Práticas para Serviços de Alimentação. Diário Oficial da União, Brasília (DF). 200416 set.; Seção 1:25.

[18] Brasil. Ministério da Saúde. Agência Nacional de Vigilância Sanitária. Portaria $n^{\circ}$. 817, de 10 de maio de 2013. Aprova as diretrizes nacionais para a elaboração e execução do projeto-piloto de categorização dos serviços de alimentação para a Copa do Mundo FIFA 2014. Diário Oficial da União, Brasília (DF). 201313 mai.; Seção 1:44.

[19] Brasil. Ministério da Saúde. Agência Nacional de Vigilância Sanitária. RDC nº. 10, de 12 de março de 2014. Dispõe sobre os critérios para a categorização dos serviços de alimentação. [Internet]. Diário Oficial da União, Brasília (DF). 201412 mar.

[20] GEQUAL/UNIFESP. Sistema de Avaliação de Risco Sanitário módulo - alimentação coletiva, versão 1.0, 2013. Disponível em $<$ http://www.cecanebs.com.br/siars/index.html $>$

[21] Reis HF, Flávio EF, Guimarães RSP. Avaliação das condições higiênico-sanitárias de uma unidade de alimentação e nutrição hospitalar de Montes Claros, MG. Montes Claros, Rev. Unimontes cientifica. 2015 ago-dez; 17(2): 68-81.

[22] Sobral RRM, Batista RSA, Nascimento CP, Nunes EN, da Silva APV. Avaliação das condições higiênico sanitárias no mercado público de Russas, Ceará. Rev. AGROTEC. 2013; 34(1): 30-39.

[23] Lopes LL, Silveira JT, Floriano JM. Condições higiênico-sanitárias de serviços de alimentação em hotéis de Uruguaiana, Rio Grande do Sul. Nutrivisa - Revista de Nutrição e Vigilância em Saúde. 2015; 2(1): 16-21.

[24] Raimundo G, Serafim AL, Medeiros LB, Peixoto CS, Jesus NLS, Stangarlin-Fiori L. Boas Práticas em Serviços de Alimentação do Mercado Municipal de Curitiba-PR. RevInst Adolfo Lutz. São Paulo, 2015;74(3):295-300.

[25] Silveira JT, Brasil CCB, Floriano JM. Schwarzer $\mathrm{PF}$. Condições higiênicas e boas práticas de manipulação em serviços de alimentação da cidade de Itaqui-RS. Vigil. Sanit. Debate. 2015; 3(2):144149. 
[26] Rio Grande do Sul. Secretaria da Saúde. Portaria $n^{\circ} .78$, de 30 de janeiro de 2009. Aprova a Lista de Verificação em Boas práticas para Serviços de Alimentação, aprova Normas para Cursos de capacitação em Boas Práticas para Serviços de Alimentação e dá outras providências. Diário Oficial do Estado do Rio Grande do Sul, Porto Alegre (RS). 200928 jan.; Seção 1:35.

[27] Silva LC, dos Santos DB, de São José JFB, da Silva EMM. Boas práticas na manipulação de alimentos em Unidades de Alimentação e Nutrição. Demetra. 2015; 10(4): 797-820.

[28] Ponath FS, Valiatti TB,Sobral FOS, RomãoNF, AlvesGMC, Passoni GP. Avaliação da higienização das mãos de manipuladores de alimentos. RevPanAmazSaude. 2017; 7(1):63-69.

[29] Santos RMS, Gouveia DS, Rocha APT, da Silva WM, Lins ADF. Avaliação de restaurante universitário por meio do regulamento técnico de boas práticas para serviços de alimentação.Rev. Verde (Pombal - PB - Brasil). 2015 abr-jun; 10(2): $26-32$.

[30] Silva AA, Bassani L, Riella CO, Antunes MT. Manipulação de alimentos em uma cozinha hospitalar: Ênfase na segurança dos Alimentos. Caderno pedagógico, Lajeado, 2015; 12(1): 111-123.

[31] Mayra N, Silva MG, Bezerra MJ, Bezerra MQ, Santo FM, de Souza EA, et al. Condições higiênicosanitárias das unidades produtoras de alimentos em hotéis do município de Caruaru, Pernambuco. Veredas Favip ano 10. 2014; 7(2): 109-122.

[32] Monteiro MAM, Ribeiro RC, Fernandes BDA, Sousa JFR, Santos LM. Controle das temperaturas de armazenamento e de distribuição de alimentos em restaurantes comerciais de uma instituição pública de ensino. Demetra. 2014; 9(1): 99-106.

[33] Penedo AO, de Jesus RB; Silva SCF, Monteiro MAM. Ribeiro RC. Avaliação das temperaturas dos alimentos durante o preparo e distribuição em restaurantes comerciais de Belo Horizonte-MG. Demetra. 2015; 10(2): 429-440.

[34] Libânio MM, Gondim CM, Sousa JBG. Elaboração do manual de boas práticas do restaurante universitário da Universidade Federal de
Campina Grande, campus Cuité-PB. Rev. Fama de Ciências da Saúde. 2015; 1(2): 40-53. 